\title{
A quantitative assessment of body iron status and its relationship with glycemic control in patients of type 2 diabetes mellitus in a tertiary care hospital of Kolkata
}

\author{
Ananya Saha1, Pradip Mukhopadhyay², Indrajit Nath ${ }^{3}$, Arun Kumar', \\ Utpal Kumar Biswas ${ }^{5}$
}

${ }^{1}$ Demonstrator, R.G. Kar Medical College \& Hospital, Kolkata, West Bengal, India. ${ }^{2}$ Associate Professor, Department of Endocrinology. IPGMER and SSKM Hospital, Kolkata, West Bengal, India. ${ }^{3}$ Associate Professor, ${ }^{5}$ Professor and Head, Department of Biochemistry, North Bengal Medical College and Hospital, Darjeeling, West Bengal, India. ${ }^{4}$ Professor and Head, Department of Biochemistry, Jagannath Gupta Institute of Medical Science, Budge Budge, Kolkata, West Bengal, India

Background: Diabetes is one of the most common disease which is observed in every household of Indian population. The longevity of the diabetic patients is dependent upon the frequency of complication and comorbidity that they encounter. Serum iron and ferritin, both being the aggravators to the oxidative stress accelerating the development of complications, gives us the reason to venture into the territory exploring the possibility of monitoring the body iron stores and taking prevent measures to control such complication. The current study was designed with an aim to knot the relationship between body iron stores and glycemic control in patients of type-Il diabetes mellitus. Aims and Objectives: To measure the levels of serum ferritin, serum Iron, transferrin saturation and $\mathrm{HbA} 1 \mathrm{C}$ and finding out the relationship between body iron stores and glycemic control in patients of Type-II Diabetes Mellitus. Materials and Methods: A total of 50 diagnosed cases of type II DM and 50 healthy controls between the age group of 35-65 years were taken following inclusion and exclusion criteria. Body iron stores were assessed by measuring serum ferritin, Serum iron and Transferrin saturation and Glycemic control was assessed by measuring levels of $\mathrm{HbA}_{1 \mathrm{c}}$. Results: A significant increase in serum ferritin, serum iron and Transferrin saturation $(P<0.001)$ was noted in diabetic patients as compared to controls. There was a positive correlation between serum iron and transferring saturation in the diabetic patients. Conclusion: The co-morbidities and complications in the Diabetic population can be prevented by monitoring Body iron stores as they can significantly contribute to the oxidative stress leading to the complication and decreased life expectancy. Early detection in the abnormality in the body iron store can help us in employing proper measures for a better management of Type-II diabetic patients and thereby improving their survival.

Key words: Serum Ferritin; Serum Iron; Transferrin Saturation; HbA 1 ; Type-II DM; Oxidative stress

Introduction: Type 2 DM (formerly known as Noninsulin dependent DM) is the most common form of DM characterized by hyperglycemia, insulin resistance, and relative insulin deficiency. ${ }^{1}$ The gigantic leap in the diabetic population is a serious health concern worldwide including in our country. The complication of diabetes is preventable in case of early diagnosis and management.
Measurement of glycated proteins primarily HbA1c (glycated hemoglobin) is effective in monitoring long-term glucose control in people with diabetes mellitus. ${ }^{2}$

Serum ferritin is an acute phase reactant, and is a marker of iron stores in the body. ${ }^{3}$ Raised serum ferritin may possibly be related to the occurrence of long term complications 
of diabetes, both microvascular and macrovascular ${ }^{4,5}$ also elevated iron stores may induce diabetes through a variety of mechanisms, including oxidative damage to pancreatic beta cells, impairment of hepatic insulin extraction by the liver, and interference with insulin's ability to suppress hepatic glucose production. ${ }^{6}$ Recent studies have shown that serum ferritin was proportional to serum glucose concentration, diastolic blood pressure, HDL cholesterol, and insulin resistance. In fact, the higher the ferritin levels, the higher the incidence of type 2 diabetes mellitus. ${ }^{7}$

Hence, this study was carried out to assess quantitatively the body iron status and its relationship with glycemic control in patients of Type 2 diabetes mellitus in a tertiary care hospital focussing to those group of population in whom such type of data was lacking.

\section{MATERIALS AND METHODS}

The present study was conducted in the Department of Biochemistry, Department of Medicine and Department of Obstetrics and Gynaecology, IPGMER and SSKM hospital, Kolkata, on 50 patients between the age group of 35-65 years of type 2 diabetes mellitus, diagnosed as per criteria of American diabetes association are taken for the study from the outdoor and Indoor of Department of Medicine, SSKM Hospital. Fifty age-sex matched healthy controls were included as control. Patients with a history overt thyroid dysfunction, chronic kidney disease, chronic liver disease, on corticosteroid therapy trauma, instrumentation, familial haemochromatosis, liver disease, any recent infection, infectious disease, malignancy and iron replacement therapy were excluded from the current study. The Study protocol was approved by Research and Ethical committee, IPGMER and SSKM hospital, Kolkata. Oral informed consents were obtained from all subjects prior to the start of the study. By taking all aseptic and antiseptic precautions, $3 \mathrm{ml}$ of blood was drawn from the anti-cubital veins of the patients. Serum Ferritin was estimated by immunoenzymometric assay (ELISA), serum iron was estimated by Ferrozine method, Serum TIBC was estimated by Chromazurol B dye using colorimetric

\begin{tabular}{|c|c|c|c|c|}
\hline Parameters & $\begin{array}{c}\text { Diabetic } \\
\text { Patient (Mean) }\end{array}$ & $\begin{array}{l}\text { Control } \\
\text { (Mean) }\end{array}$ & T-Value & P-Value \\
\hline HbA1c (\%) & 7.8 & 4.7 & 17.3 & $0.000^{*}$ \\
\hline Ferritin (ng/mL) & 99.5 & 26.5 & 13.9 & $<0.001^{*}$ \\
\hline Iron $(\mu \mathrm{g} / \mathrm{dL})$ & 85.2 & 61.5 & 14.9 & $<0.001^{*}$ \\
\hline $\begin{array}{l}\text { Transferrin } \\
\text { saturation (\%) }\end{array}$ & 32.6 & 21.6 & 20.1 & 0.015 \\
\hline
\end{tabular}

method and Glycated Hemoglobin $\left(\mathrm{HbA}_{1 \mathrm{C}}\right.$ ) was estimated by Latex Enhanced Immunoturbidometric method. The percentage saturation of transferrin with iron is calculated by dividing the serum iron concentration by the total iron binding capacity (TIBC) and multiplying by 100 .

After the biochemical estimations, the results which were obtained were statistically analyzed by using statistical software, SPSS, 16. The results which were obtained were presented as Mean \pm SD and they were then compared between different groups of study by applying Students ' $\mathrm{t}$ '- test. A probability (p) of less than 0.05 was considered as significant. Correlations were observed on using linear regression analysis.

\section{RESULTS}

Comparison of means of the different parameters (Table:1) revealed significantly higher values of $\mathrm{HbA}_{1 \mathrm{C}}$, Ferritin, Iron and Transferrin saturation in diabetic patients as compared to control.

Table 2 shows correlation between various parameters in the Diabetic patients. A positive correlation between $\mathrm{HbA}_{1 \mathrm{C}}$ and Iron and also between $\mathrm{HbA}_{1 \mathrm{C}}$ and Ferritin can be seen in the Diabetic Patients. Figures 1-3 shows the correlational plot between $\mathrm{HbA}_{1 \mathrm{C}}$, Ferritin, Iron and transferrin saturation in the Diabetic patients.

\section{DISCUSSION}

The results of the present study indicates that patients with type 2 diabetes have significant increased $(\mathrm{P}<0.000)$ ferritin levels in patients (mean $=99.5 \mathrm{ng} / \mathrm{ml}$ ) than the controls (mean $=26.5 \mathrm{ng} / \mathrm{ml}$ ). Though the relationship of ferritin with $\mathrm{HbA1C}$ in the patients has not been significant (Figure 1) but a positive trend $(\mathrm{R}=0.156, \mathrm{P}=0.280)$ indicates that type 2 diabetes patients are associated with increased ferritin. Significant correlation between ferritin and $\mathrm{HbA}_{1 \mathrm{C}}$ has not been established in the study may be due to very smaller number of sample size.

The abnormalities in Ferritin metabolism following glycation in hyperglycemic state might be a primary cause of hyperferritinaemia in type 2 DM (Glycated Ferritin has longer half-life). Glycation of transferrin decreases its

$\begin{aligned} & \text { Table: } 2 \text { Correlation between various parameters } \\
& \text { in the cases (Diabetic Patients) }\end{aligned}$
\begin{tabular}{lcc} 
Parameters & Correlation \\
Correlated & Coefficient & $\begin{array}{c}\text { Pearson's correlation } \\
\text { significance }\end{array}$ \\
\hline $\mathrm{HbA}_{1 \mathrm{C}}$ vs Iron & 0.4 & 0.004 \\
$\mathrm{HbA}_{1 \mathrm{C}}$ vs Ferritin & 0.156 & 0.280 \\
$\mathrm{HbA}_{1 \mathrm{C}}$ vs Transferrin & 0.34 & 0.015 \\
saturation (TS) & & \\
\hline
\end{tabular}




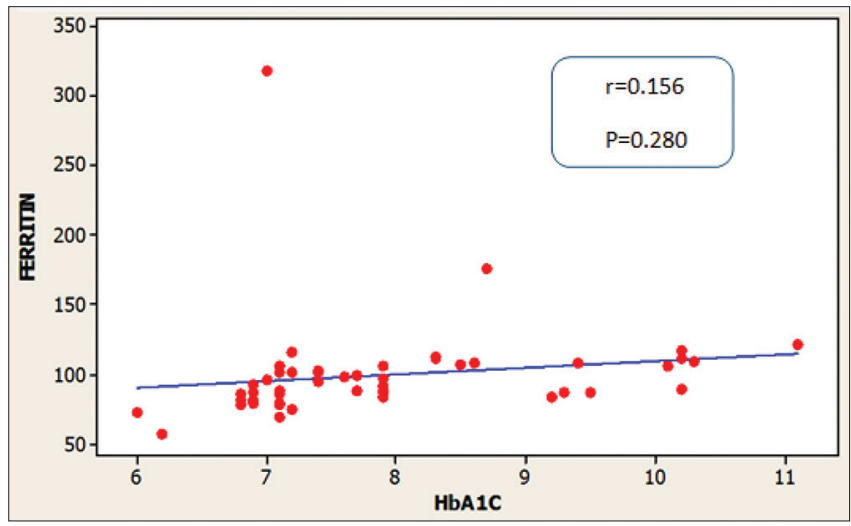

Figure 1: Correlations between $\mathrm{HbA}_{1 \mathrm{C}}$ and Ferritin in type 2 diabetic patients

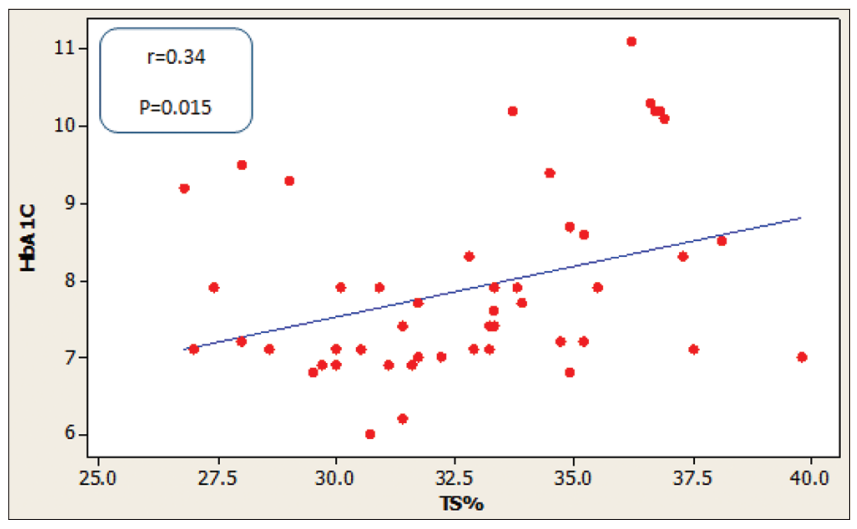

Figure 2: Correlations between $\mathrm{HbA}_{1 \mathrm{C}}$ and TS\% in type 2 diabetic patients ability to bind ferrous ion and by increasing the pool of free iron and stimulates Ferritin synthesis. Thus, type $2 \mathrm{DM}$ is associated with abnormalities of Ferritin metabolism resulting in parallel increase of serum Ferritin levels., ${ }^{8,9}$ Hyperferritininemia is present in $6.6 \%$ of unselected patients with type 2 diabetes. ${ }^{10}$ Serum concentrations of ferritin are usually increased in poorly controlled type 1 and type 2 diabetic subjects, and ferritin has been shown to predict $\mathrm{HbA}_{1 \mathrm{c}}$ independently of glucose, ${ }^{11}$ probably reflecting increased oxidative stress. Short-term improvement in glycemic control is followed by variable decreases in serum ferritin concentration.

The iron and transferrin saturation levels have also shown significant increase $(p<0.0001)$ in Type 2 Diabetic patients than the healthy control groups. As per the study mean iron level in patients were $85.2 \mu \mathrm{g} / \mathrm{dl}$ whereas in controls it was $61.5 \mu \mathrm{g} / \mathrm{dl}$. Simultaneously the mean transferrin saturation in patients were found to be $32.6 \%$ and in otherwise healthy control groups $21.6 \%$. The relationship between $\mathrm{HbA}_{1 \mathrm{C}}$ and iron (Figure 4) shows a significant positive correlation. The relationship between $\mathrm{HbA}_{1 \mathrm{C}}$ and transferrin saturation (Figure 2) also shows a significant positive correlation.

The increase in the level of iron and there by transferrin saturation can be explained by reduction in the antioxidant level and increase in oxidative stress in diabetes and anaerobiosis which facilitates rapid release of iron from

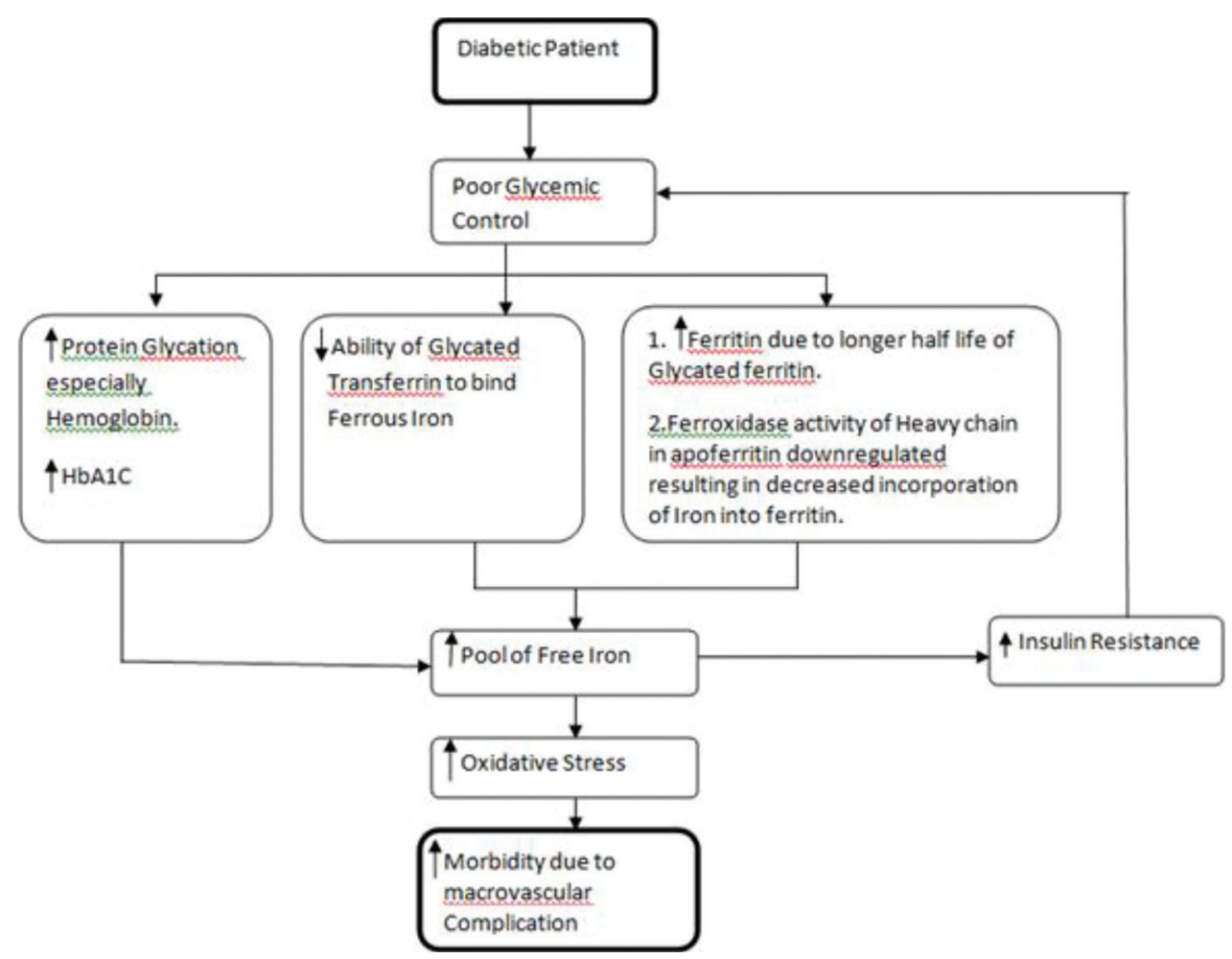

Figure 3: Summary flowchart depicting reasons for the generation of Free Iron in Diabetic patients leading to increased oxidative stress which further leads to increased morbidity due to macrovascular complication 


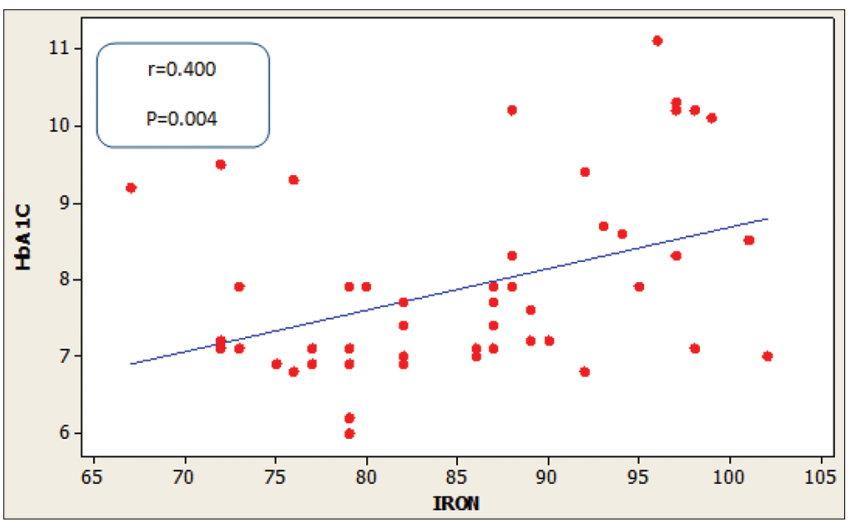

Figure 4: Correlations between $\mathrm{HbA}_{1 \mathrm{C}}$ and Iron in type 2 diabetic patients

ferritin. The ferroxidase activity of the heavy chain is downregulated in diabetes thereby decreasing the incorporation of iron into ferritin.

The heavy chain in the apoferritin molecule exerts ferroxidase activity, catalyzing the oxidation of $\mathrm{Fe}^{2+}$ into $\mathrm{Fe}^{3+}$, which prevents iron-induced cyclic red-ox reactions that would spread and amplify the oxidative damage. This activity occurs under aerobic conditions, allowing the storage of intracellular iron. When concentrations of antioxidants are low, the reducing potential and anaerobiosis progressively increase, facilitating a rapid release of iron from ferritin. Additionally, the ferroxidase activity in the heavy chain is downregulated in this setting, decreasing the incorporation of iron into ferritin. The overall result of oxidative reactions is an increase in the availability of free iron from the ferritin molecule as well as from other molecules undergoing degradation, such as the heme group. These events, in turn, can enhance and amplify the process of generation of free radicals, causing cellular and tissue damage. The oxidative stress also downregulates the affinity of IRE for IRE-BP. Thus, ferritin can act both as a source or iron, which induces oxidative stress, and as a mechanism that protects against iron toxicity. ${ }^{12}$

The effect of increase in iron levels may be explained in two different ways. Firstly, iron stores in the pancreas may lead to defective synthesis and secretion of insulin. ${ }^{13}$ Secondly, excess iron deposition culminates in hyperinsulinemia due to obstruction in the insulin withdrawing ability of the liver. ${ }^{14}$ Such deposits hinder insulin action, resulting in insulin resistance, which suppresses the yield of glucose in the liver. ${ }^{15} \mathrm{~A}$ similar trend has been observed in previous studies. ${ }^{16-20}$ Poor glycaemic control is the root cause of escalated protein glycation-especially haemoglobin, which restores the free state of iron. This amplified free iron pool revitalizes oxidant generation, conferring damage to biomolecules and leading to complications. ${ }^{21}$
Iron is intimately linked to oxidative stress. Iron participates, through the Fenton reaction, in the formation of highly toxic free radicals, such as hydroxide and the superoxide anion, which are capable of inducing lipid peroxidation. ${ }^{22}$ The general effect of catalytic iron is to convert poorly reactive free radicals, such as $\mathrm{H}_{2} \mathrm{O}_{2}$, into highly reactive ones, such as $\mathrm{OH}^{-}$and $\mathrm{O}_{2}$. Free radicals and other oxidation by-products are well known factors that impair the mechanisms of vasodilatation ${ }^{23}$ and cause endothelial depletion of endogenous antioxidants, such as ascorbic acid. ${ }^{24}$ Iron chelation blocks oxidation of LDL, and iron released from heme and ferritin favours oxidation of this lipoprotein. ${ }^{25}$ Increased iron availability is, theoretically, expected to contribute to macrovascular disease because iron has an adverse effect on endothelium ${ }^{26}$ and accelerates the development of atherosclerosis. ${ }^{27}$

Elevated transferrin saturation in the diabetic subjects of our study hints at ineffective erythropoiesis and accumulation of iron in human tissues, which hampers insulin action. ${ }^{21}$

As demonstrated in three independent studies, transferrin saturation can act as an independent risk marker for any form of diabetes mellitus, and a value of $>=50 \%$ elevates the risk of developing T2DM by two to three times. ${ }^{28}$ Such findings have linked elevated transferrin saturation in T2DM patients with earlier age of onset, and our results reflect the same.

The findings of this study project that estimation of serum Ferritin may be useful in screening diabetics with poor glycemic control who are at high risk of developing complications. Thus, serum Ferritin estimations in type 2 $\mathrm{DM}$, can be one of the adjuvant aids in investigations which guides in taking timely medical intervention and preventing further progression of disease.

\section{CONCLUSION}

The findings of the present study suggests that there is increase in the level of ferritin, serum iron and transferrin saturation in diabetes patients as compared to normal controls. Increase in the levels of serum iron and ferritin indicates the level of oxidative stress in the diabetic population which further leads to microvascular and macrovascular complication. Proper monitoring of the body iron stores in diabetic population which includes serum ferritin, serum iron and transferrin saturation can give us input towards the development of complications and co morbidities and help us instituting proper preventive measures to reduce the oxidative stress 
and thereby improving the quality of health in diabetic population.

\section{ACKNOWLEDGEMENT}

The authors take this opportunity to thank Department of Endocrinology and Department of Biochemistry, IPGMER and SSKM Hospital, Kolkata for their hole hearted support for the study.

\section{REFERENCES}

1. Maitra A and Abbas AK. Endocrine system. In: Kumar V, Fausto N, Abbas AK (eds). Robbins and Cotran Pathologic basis of disease .7th ed. Philadelphia: Saunders;2005. 1156-1226.

2. David B. Sacks. Diabetes mellitus. In: Carl A. Burtis, Edward R. Ashwood, David E. Bruns, eds. Tietz Textbook of Clinical Chemistry and Molecular Diagnostics. 5th ed. Missouri, USA: Elsevier; 2012.1415-1451.

https://doi.org/10.1016/B978-1-4160-6164-9.00046-9

3. Koorts $A M$ and Viljoen M. Acute phase proteins: Ferritin and ferritin isoforms. University of Petoria, South Africa .2011; 154-184.

4. Kim NH. Serum ferritin in healthy subjects and type 2 diabetes mellitus. Med Korea. 2000; 41: 387-392.

https://doi.org/10.3349/ymj.2000.41.3.387

5. Eshed I, Elis A and Lishner M. Plasma ferritin and type 2 diabetes mellitus. Endocr Res .2001; 27: 91-97.

https://doi.org/10.1081/ERC-100107172

6. Sharifi F, Nasab NM and Zadeh HJ. Elevated serum Ferritin concentrations in prediabetic subjects. Diabetes Vascular diseases Res. 2008;5(1):15 -18.

https://doi.org/10.3132/dvdr.2008.003

7. Forouhi NG, Harding AH, Allison M, Sandhu MS, Welch A, Luben $\mathrm{R}$, et al. Elevated serum ferritin levels predict new-on $\urcorner$ set type 2 diabetes: results from the EPIC-Norfolk prospective study. Diabetologia. 2007; 50: 949-956.

https://doi.org/10.1007/s00125-007-0604-5

8. Kim NH, Oh JH, Choi KM, Kim YH, Baik SH, Choi DS, et al. Serum Ferritin in healthy subjects and Type 2 diabetic patients. Yonsei Medical Journal. 2000; 41(3):387-392.

https://doi.org/10.3349/ymj.2000.41.3.387

9. Forouchi NG and Harding AH. Elevated serum Ferritin levels predict new-onset Type 2 diabetes : results from the EPICNorflok Prospective Study. Springer-Verlag. 2007; 50: 949-956. https://doi.org/10.1007/s00125-007-0604-5

10. O'Brien T, Basset B, Burray DM, Dinneen S and O'Sullivan DJ. Usefulness of biochemical screening of diabetic patients for hemochromatosis. Diabetes Car.1990;13:532-534.

https://doi.org/10.2337/diacare.13.5.532

11. Fernández-Real JM, Ricart W, Arroyo E, Balança R and Casamitjana R Cabrero D. Serum ferritin as a component of the insulin resistance syndrome. Diabetes Care.1998;21:62-68. https://doi.org/10.2337/diacare.21.1.62

12. Juckett MB, Balla J, Balla G, Jessurun J, Jacob HS and Vercellotti GM. Ferritin protects endothelial cells from oxidized low-density lipoprotein in vitro. Am J Pathol.1995;147:782-789.

13. DeFronzo RA. The triumvirate: B-cell, muscle, liver. A collusion responsible for niddm. Diabetes.1988;37:667-687. https://doi.org/10.2337/diab.37.6.667

14. Forouhi NG, Harding AH, Allison M, Sandhu MS, Welch A, Luben $\mathrm{R}$, et al. Elevated serum ferritin levels predict new-onset type 2 diabetes: Results from the epic-norfolk prospective study. Diabetologia .2007; 50: 949-956. https://doi.org/10.1007/s00125-007-0604-5

15. Wlazlo N, van Greevenbroek MM, Ferreira I, Jansen EH, Feskens EJ, vanderKallen CJ, et al. Iron metabolism is prospectively associated with insulin resistance and glucose intolerance over a 7-year follow-up period: The CODAM study. Acta Diabetol. 2015;52: 337-348. https://doi.org/10.1007/s00592-014-0646-3

16. Dulal HP, Lamsal M, Sharma SK, Baral N and Majhi SS. Status of iron, oxidant and antioxidants in chronic type 2 diabetes mellitus patients. Nepal Med Coll J. 2014;16:54-57.

17. Sudhakar B, Toshniwal P, Shah R and Toshniwal S. Elevated serum ferritin and serum free iron-A novel marker for pre-diabetes Type 2 in relationship with HbA1c. J Med Sci Technol. 2014;3:61-66.

18. Gohel M, Sirajwala HB and Chacko A. Serum free iron concentration in patients with type 2 diabetes mellitus with good and poor control and its correlation with glycemic control. Int J Diabetes Res. 2013;2:33-38.

19. Atari-Hajipirloo S, Valizadeh N, Ansari MHK, Rasmi $Y$ and Kheradmand F. Altered concentrations of copper, zinc, and iron are associated with increased levels of glycated haemoglobin in patients with type 2 diabetes mellitus and their first-degree relatives. Int J Endocrinol Metab. 2016;14(2):e33273.

https://doi.org/10.5812/ijem.33273

20. Perumal M, Lakshmanan AMG, Ragavan KP and Ravi R. Association of serum free iron and glycemic control among type II diabetes mellitus population in Puducherry-A preliminary study. Int J Med Sci Public Health. 2016;5:2479-2482. https://doi.org/10.5455/ijmsph.2016.23042016499

21. Opara EC. Role of oxidative stress in the etiology of type II diabetes and the effect of antioxidant supplementation on glycemic control. J Investig Med. 2004; 52: 19-23. https://doi.org/10.1097/00042871-200401000-00022

22. Fernández-Real JM, López-Bermejo A and Ricart W. CrossTalk Between Iron Metabolism and Diabetes. Diabetes. 2002; 51(8): 2348-2354. https://doi.org/10.2337/diabetes.51.8.2348

23. Graier WF, Simecek S, Kukovetz WR and Kostner GM. High D-glucose-induced changes in endothelial $\mathrm{Ca} 2+1$ EDRF signalling are due to generation of superoxide anions. Diabetes.1996; $45: 1386-1395$. https://doi.org/10.2337/diab.45.10.1386

24. Yue DKS, McLennon S, Fisher E, Heffernan S, Capogreco C and Ross GR. Ascorbic acid status and polyol pathway in diabetes. Diabetes.1989; 38: 257 -261. https://doi.org/10.2337/ diabetes.38.2.257

25. Abdalla DSP, Campa A and Monteiro MP. Low density lipoprotein oxidation by stimulated neutrophils and ferritin. Atherosclerosis.1992;97:149-159. https://doi.org/10.1016/0021-9150(92)90128-4

26. Lekakis J, Papamicheal C, Stamatelopoulos K, Cimponeriu A, Voutsas A, Vemmos K, et al. Hemochromatosis associated with endothelial dysfunction: evidence for the role of iron stores in early atherogenesis. Vasc Med. 1989;4:147-148. https://doi.org/10.1191/135886399675689098

27. Araujo JA, Romano EL, Brito BE, Parthe V, Romano M, Bracho $\mathrm{M}$, et al. Iron overload augments the development of atherosclerotic lesions in rabbits. Arterioscler Thromb Vasc Biol.1995;15:1172-1180 
https://doi.org/10.1161/01.ATV.15.8.1172

28. Ellervik C, Mandrup-Poulsen T, Andersen HU, TybjaergHansen A, Frandsen M, Birgens $\mathrm{H}$, et al. Elevated transferrin saturation and risk of diabetes: Three population-based studies. Diabetes Care. 2011;34:2256-2258.

https://doi.org/10.2337/dc11-0416

Authors Contribution:

AS, UKB-Concept and design of the study, prepared first draft of manuscript; PM-Interpretation of results, literature review; IN-Coordination, review of literature, final manuscript preparation; UKB,AK-Statistically analyzed and interpretation and revision of manuscript, final approval

Work attributed to:

Institute of Post Graduate Medical Education and Research and SSKM Hospital, Kolkata

\section{Orcid ID:}

Dr Ananya Saha- (i) https://orcid.org/0000-0003-3430-358X

Dr. Indrajit Nath- (1) https://orcid.org/0000-0002-6807-6736

Prof. Dr. Arun Kumar- (iD http://orcid.org/0000-0002-8800-0296

Prof. Dr. Utpal Kumar Biswas- (1) https://orcid.org/0000-0002-4714-0065

Source of Funding: None. Conflict of Interest: None. 